\title{
Prevalence of menstrual disorder among college girls and correlation with body mass index
}

\author{
Jeevitha K. J.*, Rajarajeswari S.
}

Department of Obstetrics and Gynecology, Velammal Medical College, Madurai, Tamil Nadu, India

Received: 25 March 2019

Accepted: 04 May 2019

*Correspondence:

Dr. Jeevitha K. J.,

E-mail: jeevithakj@yahoo.co.in

Copyright: (c) the author(s), publisher and licensee Medip Academy. This is an open-access article distributed under the terms of the Creative Commons Attribution Non-Commercial License, which permits unrestricted non-commercial use, distribution, and reproduction in any medium, provided the original work is properly cited.

\begin{abstract}
Background: Menstrual irregularity is the most common gynaecological disorder in all age group. Adolescence is a transitional period between childhood and adulthood and involves physical, biological and psychosexual changes and is characterized by hormonal changes. Aim of this study was to find out the prevalence of menstrual abnormality in college girls in Madurai and their association with their Body mass Index (BMI).

Methods: A cross sectional study was conducted among 200 girls of age group 18-22 years in a college in Madurai after getting their consent from college authorities and students. All details regarding their age of menarche, type of menstrual disorder and their BMI, stress factors were collected. The results were compared using chi square test and the pattern of menstrual abnormality and its relation with BMI and with stress was obtained.

Results: The average age of menarche was 13.38 years in our study, irregular cycle was present in $47.5 \%$, dysmenorrhoea was the commonest disorder and accounts for $26 \%$ students requiring medical treatment. Underweight students have irregular cycles compared to other groups. Stress had a significant correlation with menstrual irregularity.

Conclusions: Many students in our study was under obese category, lifestyle modification like regular exercise, avoiding junk food and promoting healthy eating habits should be emphasised among students to have a healthy life. Students should also be informed about menstruation, physiological changes and its importance.
\end{abstract}

Keywords: Adolescence, BMI, Menstrual disorder, Stress

\section{INTRODUCTION}

Menstrual irregularity is the most common gynaecological disorder in adolescent group. Adolescence is a transitional period between childhood and adulthood and involves physical, biological and psychosexual changes and is characterized by hormonal changes. Hormone imbalance is due to immature Hypothalamic-pituitary-ovarian axis, thyroid dysfunction, and polycystic ovarian syndrome. Some of the common problems that the adolescent girls encounter are dysmenorrhoea, menstrual flow disorder and premenstrual symptoms. $75 \%$ of the adolescent girls encounter some problems associated with menstruation. ${ }^{1}$ Dysmenorrhoea is the most common in young girls which is defined as painful menstrual flow. ${ }^{2}$ Pre- menstrual syndrome (PMS) is defined as collection of physical and psychological symptoms that the girl experience during luteal phase of the menstrual cycle. More than $90 \%$ of these problems are preventable by early diagnosis and proper treatment. ${ }^{3}$

An etiological relationship exists between menstrual problems, BMI, dietary habits, exercise and psychological stress. ${ }^{4}$ The aim of the study is to find out the prevalence of menstrual abnormality in college girls 
in Madurai and their correlation with their BMI and psychological stress with their menstrual disorder.

\section{METHODS}

This is a cross sectional study done at Shautrastra girls college in Madurai belonging to 18-22 years after taking consent from the college authorities and ethical committee of our hospital. Students and college authorities were explained about the purpose of the study and questionnaires were distributed to those willing to take part in the study. Details regarding their age of menarche, menstrual disorder (dysmenorrhoea, menorrhagia, oligomenorrhoea, pre-menstrual syndrome) and stress factors were collected. Anthropometric data (height and weight was measured). BMI was calculated by the formula weight in kilogram divided by height in metres squared $\left(\mathrm{kg} / \mathrm{m}^{2}\right)$. Students who did not attain menarche, who have some health problems and those not willing for the study were excluded from the study.

For the study, authors decided the following definition. Regular menstrual cycle is prior 3 cycles regular with normal flow (3-5 days) with regular cycle length (22-35 days). Irregular cycle is abnormality in length of the cycle either less than 22 days or more than 35 days cycle. Menorrhagia is defined as bleeding either more than 8 days or heavy flow with clots passage or using more than 5 pads per day. Dysmenorrhoea is painful menstrual cycle. In this study, dysmenorrhoea is considered as painful menstruation seeking medical treatment. Pre- menstrual symptoms are head ache, bloating, nausea, breast tenderness, swelling of extremities or pain abdomen in the luteal phase of the cycle. Emotional symptoms like irritability, anger, depression, anxiety were also collected.

\section{Statistical analysis}

Prevalence of each menstrual disorder was calculated. Comparison between BMI and stress with menstrual irregularity was also calculated. Statistical analysis was done using SPSS software and $\mathrm{p}$ value $<0.05$ was considered as statistically significant.

\section{RESULTS}

Among 200 students participated in the study the average age of menarche is 13.38 years. Most of the students had normal menstrual cycle 104 students (52\%), 52students (26\%) had dysmenorrhoea which is the most common disorder presented. 50 students $(25 \%)$ had irregular cycles with or without dysmenorrhoea and 150 students (75\%) had regular cycles. Among irregular cycles 19 students $(9.5 \%)$ had oligomenorrhoea, 17 students $(8.5 \%)$ had menorrhagia and only 8 students $(4 \%)$ complained of pre-menstrual syndrome.

The total number of students with normal BMI was 42 (21\%), 4 students fall underweight constituting $2 \%$, overweight were 62 students $(31 \%)$ and obese were 92 students (46\%). Stress was present in 43 students $(21 \%)$.

Table 1: Descriptive statistics.

\begin{tabular}{|llllll|}
\hline Age & Total number & Minimum & Maximum & Mean & Std. Deviation \\
\hline Age & 200 & 18 & 29 & 19.62 & 1.137 \\
\hline Age of menarche & 200 & 11 & 16 & 13.38 & 1.029 \\
\hline
\end{tabular}

Table 2: Type of Menstrual disorder.

\begin{tabular}{|lll|}
\hline Type & Frequency & Percent \\
\hline Dysmenorrhoea & 52 & 26 \\
\hline Menorrhagia & 17 & 8.5 \\
\hline Normal & 104 & 52 \\
\hline Oligomenorrhoea & 19 & 9.5 \\
\hline Premenstrual syndrome & 8 & 4 \\
\hline Total & 200 & 100 \\
\hline
\end{tabular}

Our aim of the study is to find the correlation between BMI and menstrual disorder. We found that irregular cycle was common in students with BMI $<18.5,50 \%$ of them had menorrhagia, whereas only 25 students $(59.5 \%)$ had irregular cycles in normal weight category. Among overweight group $45.2 \%$ students had irregular cycle and $42.4 \%$ students had irregular cycle among obese group. Menorrhagia was the common finding seen in students with BMI <18.5. Among normal weight students $40.5 \%$ had normal cycle, $35.7 \%$ had dysmenorrhoea, $4.8 \%$ had menorrhagia, $14.3 \%$ had oligomenorrhoea and $4.8 \%$ had pre- menstrual syndrome. Among overweight and obese group most common disorder was dysmenorrhoea which was $22.8 \%$ and $26 \%$ respectively, menorrhagia was present in $8.7 \%$ in overweight and $8.5 \%$ in obese group. 
Stress factors had a significant correlation with menstrual irregularity. Irregular cycle was present in $72.1 \%$ of students with stress whereas only $40.8 \%$ had irregular cycle in those with no significant history of stress.

Table 3: BMI and its relation with menstrual disorder.

\begin{tabular}{|c|c|c|c|c|c|c|c|c|}
\hline \multirow{2}{*}{ BMI } & & & \multicolumn{5}{|l|}{ Type } & \multirow{2}{*}{ Total } \\
\hline & & & Dysmenor & Menorr & Normal & Oligo & Premens & \\
\hline \multirow{8}{*}{ BMI } & \multirow{2}{*}{$<18.5$} & Count & 1 & 2 & 1 & 0 & 0 & 4 \\
\hline & & $\%$ & $25.0 \%$ & $50.0 \%$ & $25.0 \%$ & $0.0 \%$ & $0.0 \%$ & $100.0 \%$ \\
\hline & \multirow{2}{*}{$18.5-24.9$} & Count & 15 & 2 & 17 & 6 & 2 & 42 \\
\hline & & $\%$ & $35.7 \%$ & $4.8 \%$ & $40.5 \%$ & $14.3 \%$ & $4.8 \%$ & $100.0 \%$ \\
\hline & \multirow{2}{*}{$25.0-29.9$} & Count & 15 & 5 & 33 & 7 & 2 & 62 \\
\hline & & $\%$ & $24.2 \%$ & $8.1 \%$ & $53.2 \%$ & $11.3 \%$ & $3.2 \%$ & $100.0 \%$ \\
\hline & \multirow{2}{*}{$>=30$} & Count & 21 & 8 & 53 & 6 & 4 & 92 \\
\hline & & $\%$ & $22.8 \%$ & $8.7 \%$ & $57.6 \%$ & $6.5 \%$ & $4.3 \%$ & $100.0 \%$ \\
\hline \multirow{2}{*}{ Total } & & Count & 52 & 17 & 104 & 19 & 8 & 200 \\
\hline & & $\%$ & $26.0 \%$ & $8.5 \%$ & $52.0 \%$ & $9.5 \%$ & $4.0 \%$ & $100.0 \%$ \\
\hline
\end{tabular}

Table 4: Stress and relation with menstrual disorder.

\begin{tabular}{|c|c|c|c|c|c|}
\hline \multirow{2}{*}{ Stress } & & & \multicolumn{2}{|c|}{ Disorderly } & \multirow{2}{*}{ Total } \\
\hline & & & No & Yes & \\
\hline \multirow{4}{*}{ Stress } & \multirow{2}{*}{ No } & Count & 93 & 64 & 157 \\
\hline & & $\%$ & $59.2 \%$ & $40.8 \%$ & $100.0 \%$ \\
\hline & \multirow{2}{*}{ Yes } & Count & 12 & 31 & 43 \\
\hline & & $\%$ & $27.9 \%$ & $72.1 \%$ & $100.0 \%$ \\
\hline \multirow{2}{*}{\multicolumn{2}{|c|}{ Total }} & Count & 105 & 95 & 200 \\
\hline & & $\%$ & $52.5 \%$ & $47.5 \%$ & $100.0 \%$ \\
\hline
\end{tabular}

\section{DISCUSSION}

Menstruation is important part of normal sexual and reproductive health. The changes in menstrual cycle in reproductive age affect physical and psychological wellbeing. The mean age of menarche in present study was 13.38 years (Table 1) which was consistent with study conducted by ShabnamOmidvar and Khyrunnisa begum $(13.4 \pm 1.2$ years) and study conducted by Solanki $\mathrm{H}$ and Vibha G (14.5 years). ${ }^{5,6}$ In another study conducted by Nirmal JL it was $12.6 \pm 1.32$ years which was less when compared our study. ${ }^{7}$ The age of menarche depends on constitutional, nutritional, socioeconomic and general health of the students.

In this study, $47.5 \%$ had irregular cycle and $52.5 \%$ had regular cycles which were comparable with study conducted in Nigeria found to have regular cycles in $63.5 \%$ and $36.5 \%$ had irregular cycle. ${ }^{8}$ Another study had $34.6 \%$ with irregular cycle conducted by Ekpenyong CE. ${ }^{9}$ Whereas study conducted by Nirmala JL had on $29 \%$ students with irregular cycle. ${ }^{7}$ Dysmenorrhoea was the commonest disorder present in our study $26 \%$ (Table 2) which was compared with the study conducted by Solanki H, were $26.7 \%$ students had dysmenorrhoea which require medical treatment. ${ }^{6}$ It was also comparable with study conducted by Nirmala JL were $30 \%$ require medical treatment. ${ }^{7}$ Dysmenorrhoea was significantly present among students with normal body weight $35.7 \%$ (Table 3) which was comparable with study conducted by Begum $\mathrm{J}$ et al. ${ }^{10}$ In the present study irregular cycle was common among students with BMI <18.5 (75\%) which was not comparable with other studies. Menorrhagia was present in $50 \%$ of them which was not compared with other studies. Other studies have a significant correlation with increased BMI and irregular cycles. Some studies have no significant correlation between BMI and menstrual irregularity. ${ }^{11}$ Stress had a significant correlation with menstrual irregularity. In our study $72.1 \%$ had irregular cycle in students with history of stress (Table 4) which was comparable with study conducted by Esimai et al, which were around 30-50\%. ${ }^{12}$ Most of the students experienced menstrual problems nearing the examination and thus confirms that stress has a major role in menstrual disorders.

\section{CONCLUSION}

Many students in our study was under obese category, lifestyle modification like regular exercise, avoiding junk food and promoting healthy eating habits should be emphasised among students to have a healthy life. 
Students should also be informed about menstruation, physiological changes and its importance. There are some limitations in the study were socioeconomic status and family details were not collected.

\section{ACKNOWLEDGMENTS}

Authors would like to thank the principal and the students for providing permission and participation of the students to conduct the study.

Funding: No funding sources Conflict of interest: None declared

Ethical approval: The study was approved by the Institutional Ethics Committee

\section{REFERENCES}

1. Lee LK, Chen PCY, Lee KK. Menstruation among adolescent girls in Malaysia: a cross sectional school survey. Singapore Med J. 2006;47(10):869-74.

2. Rupaveni, Veena KS, Subithal L. Menstrual abnormalities in school going girls- Are they related to dietary and exercise pattern? J Clin Diagn Res. 2013;7(11):2537-40.

3. Mohite RV, Mohite VR. Correlates of the menstrual problems among rural college students of Satara district. Al Ameen J Med Sci. 2013;6(3):213-8.

4. Verma PB, Pandya CM, Ramanuj VA. Menstrual pattern of adolescent school girls in Bhavnagar (Gujarat). NJIRM. 2011;2(1):30-40.

5. Shabnam O, Khyrunnisa B. Factors influencing hygienic practices during menses among girls from South India: A cross sectional study. Int J
Collaborative Res Internal Med Pub Heal. 2010:2 (12):411-23.

6. Solanki H, Gosali V, Patel H. A study of menstrual problems and practices among girls of Mahilacollege. NJIRM. 2012;3(4):24-7.

7. Nirmala JL, Jayavani RL, Nivedhana AP. A study of menstrual disorders in medical students and its correlation with biological variables. Sch J App Med Sci. 2014:2(6E):3165-75.

8. Umeora O, Egwuatu V. Age at menarche and menstrual pattern of Igbo women of Nigeria. African J Reprod Health. 2008;12(1):90-5.

9. Ekpenyong CE, Davis KJ. Academic stress and menstrual disorders among female undergraduates in Uyo, South eastern Nigeria- the need for health education. Niger J Physiol Sci. 2011:193-198.

10. Begum J, Hossain AM, Nazneen SA. Menstrual pattern and common menstrual disorders among students in Dinajpurcollege. Dinajpur Med Col J. 2009;2:37-43.

11. Singh A, Kiran D, Singh H. Prevalence and severity of dysmenorrhoea: A problem related to menstruation among first and second year female medical students. Indian J Physiol Pharmacol. 2008;52(4):389-97.

12. Esimai OA, Omoniyi E. Awarness of menstrual abnormality amongst college students in urban area of Ile-Ife, Osun state, Nigeria. Ind J Community Med. 2010;35(1):63-6.

Cite this article as: Jeevitha KJ, Rajarajeswari S. Prevalence of menstrual disorder among college girls and correlation with body mass index. Int $\mathbf{J}$ Reprod Contracept Obstet Gynecol 2019;8:2354-7. 